\title{
Corrosion inhibition of low-carbon steel in hydrochloric acid environment using a Schiff base derived from pyrrole: gravimetric and computational studies
}

\author{
A. Alamiery, (iD* E. Mahmoudi and T. Allami \\ Department of Chemical and Process Engineering, Faculty of Engineering \\ and Built Environment, University Kebangsaan Malaysia (UKM), P.O. Box: 43000, \\ Bangi, Selangor, Malaysia \\ *E-mail: dr.ahmed1975@ukm.edu.my
}

\begin{abstract}
Corrosion inhibitors are used to decrease the corrosion process of metals in acid and/or basic solutions. Corrosion inhibitors are organic molecules containing polar sites such as phosphorous, sulfur, oxygen, and/or nitrogen atoms in addition to heterocyclic and aromatic rings and conjugated p-systems. A new Schiff base derivative from pyrrole, namely $N^{\prime}$-(1phenylethylidene)-4-(1H-pyrrol-1-yl)benzohydrazide (N-PB), was synthesized from acetophenone and 4-(1H-pyrrol-1-yl)benzohydrazide. The chemical structure of the newly synthesized inhibitor molecule was confirmed by Fourier transform infrared (FT-IR) and nuclear magnetic resonance (NMR) spectroscopical techniques in addition to $\mathrm{CHN}$ (carbon, hydrogen, and nitrogen) micro-elemental analysis. It was studied as a low-carbon steel corrosion inhibitor in $1 \mathrm{M}$ hydrochloric acid solution by the weight loss and scanning electron microscopy (SEM) methods. The inhibition efficiency of the synthesized inhibitor $(\mathrm{N}-\mathrm{PB})$ reached a maximum of $94.5 \%$ at $500 \mathrm{ppm}$ concentration. The presence of $\mathrm{N}-\mathrm{PB}$ inhibitor decreases the corrosion rate $\left(C_{R}\right)$ due to the formation of a protective adsorption layer on the surface of lowcarbon steel. The adsorption of $\mathrm{N}-\mathrm{PB}$ molecules obeys the Langmuir adsorption isotherm model. The density functional theory (DFT) evaluated parameters such as HOMO (highest occupied molecular orbital), LUMO (lowest occupied molecular orbital) and the energy gap $\left(\Delta E=E_{\mathrm{HOMO}}-\mathrm{E}_{\mathrm{LUMO}}\right)$ (indicate the excellency of the corrosion inhibitor. The gravimetrical, SEM, and theoretical findings are in harmony.
\end{abstract}

Received: April 26, 2021 Published: May 31, 2021

doi: $\underline{10.17675 / 2305-6894-2021-10-2-17}$

Keywords: phenylethylidene, corrosion inhibitor, DFT, LUMO, Langmuir, low carbon steel.

\section{Introduction}

Low carbon steel is widely used due to its outstanding mechanical and chemical properties in various technical and production processes, including architecture and construction. However, the tendency to corrosion is one of the many challenges in the use of carbon steel [1-3]. Corrosion of carbon steel is an inevitable phenomenon that can be controlled. One of the main methods of preventing corrosion of low carbon steel involves the use of corrosion 
inhibitors. The use of acids in industrial clean-up operations is common in petrochemical processing and oil well operations as well as removal of mineral oxides and mineral deposits. However, the corrosive effects can be severely damaging to the acid used (hydrochloric acid) and the inhibitors used can control this process [4]. Applications of environmentally sustainable organic inhibitors have emerged to meet environmental demands. Inorganic inhibitors are also widely used for protection against corrosion of metals/alloys (e.g., mild steel) due to their high efficiency. They include chromates, molybdates, phosphates, and nitrates [5-8]. Schiff bases derived from heterocyclic compounds also have corrosion inhibiting features, apart from their environmental and biodegradable properties. Heterocyclic compounds contain high electron density centers, which leads to their adsorption by the metal surface to protect it from corrosive substances [9-11]. It can be seen that according to the Sci-Finder website, recent developments in publications on environmental and ecological inhibitors account for 50 percent of the total publications for corrosion inhibitors. Several studies have also focused on the use of environmentally safe inhibitors. Additionally, a number of scientists have focused on heterocyclic inhibitors. For instance, Al-Amiery [12] studied 2-isonicotinoyl- $N$-phenylhydrazinecarbothioamide containing a pyridine six-membered ring. Hanoon et al. [13] studied a quinoline derivative, and Al-Baghdadi et al. [14] investigated acetylthiophene thiosemicarbazone, which gave an inhibitive efficacy up to $96 \%$. The inhibitor has high electron density sites, and hence has broad application as an environmentally safe inhibitor with high efficiency that amounted to $94.5 \%$. In this work, we focused on the synthesis of a corrosion inhibitor, namely $N^{\prime}$-(1phenylethylidene)-4-(1H-pyrrol-1-yl)benzohydrazide (N-PB) for low-carbon steel in $1 \mathrm{M}$ hydrochloric acid solution. Based the experimental findings from weight loss techniques, surface morphology studies using scanning electron microscopy (SEM), and quantum chemical calculations using the density function theory (DFT), a detailed study on the inhibitory efficacy of $\mathrm{N}-\mathrm{PB}$ molecules indicated in Figure 1 has been performed.

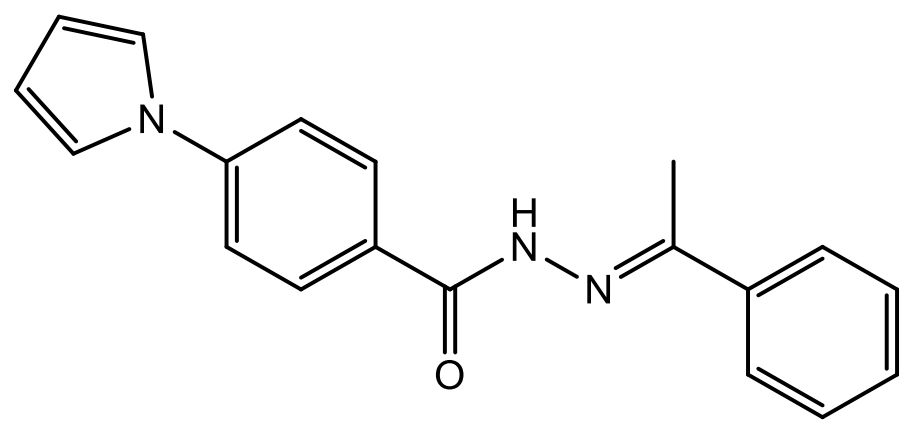

Figure 1. Chemical structure of N-PB. 


\section{Experimental}

\subsection{Materials}

The composition of low-carbon steel used in the corrosion tests is demonstrated in Table 1. Hydrochloric acid (37\%, Sigma-Aldrich Malaysia) was utilized to prepare an $1 \mathrm{M} \mathrm{HCl}$ solution by dilution with distilled water. The gravimetric tests were performed in $1 \mathrm{M} \mathrm{HCl}$ medium with various concentrations of 100, 200,300, 400, and $500 \mathrm{ppm}$ of the inhibitor studied. Emery papers of different grades were used to polish the surface of low-carbon steel coupons that were then washed with distilled water and acetone.

Table 1. Chemical composition of low-carbon steel coupons.

\begin{tabular}{cccccccc}
\hline Element & Carbon & Silicon & Phosphorus & Manganese & Sulfur & Aluminum & Iron \\
\hline Weight $\%$ & 0.210 & 0.380 & 0.090 & 0.050 & 0.050 & 0.010 & remainder \\
\hline
\end{tabular}

\subsection{Synthesis of the inhibitor}

$\mathrm{N}-\mathrm{PB}$ was synthesized by refluxing 4-(1H-pyrrol-1-yl)benzohydrazide $(0.01 \mathrm{~mol})$ with acetophenone $(0.01 \mathrm{~mol})$ for $6 \mathrm{~h}$ in ethanol $(50 \mathrm{~mL})$ using acetic acid as the catalyst, according to the Scheme demonstrated in Figure 2. The precipitate thus obtained was washed with cold ethanol, filtered, and dried. The solid was re-crystallized from ethanol to obtain a pure yellow product.
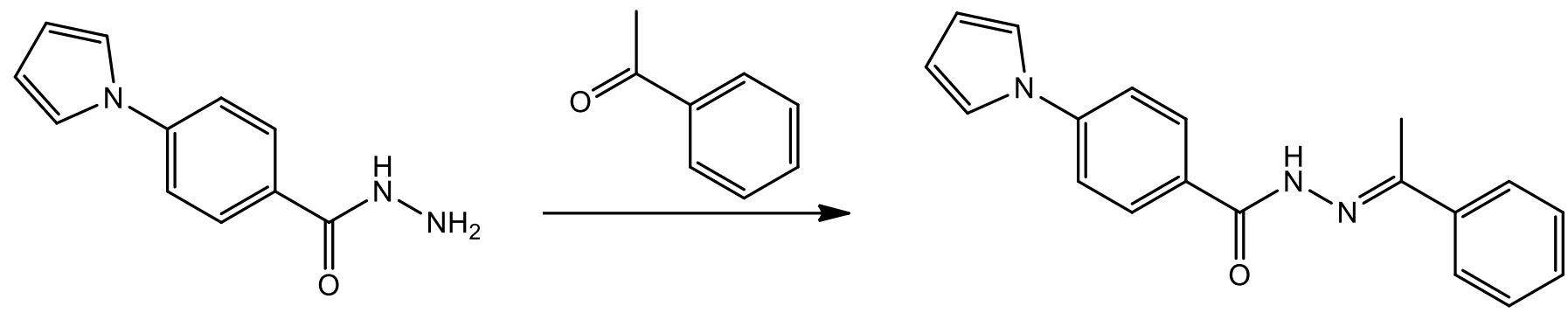

Figure 2. Scheme of N-PB inhibitor synthesis.

\subsection{Weight loss technique}

Gravimetric measurements were conducted using low-carbon steel coupons of $4.5 \mathrm{~cm} \times 2.0 \mathrm{~cm} \times 0.025 \mathrm{~cm}$ size. The gravimetric tests were carried out in $1 \mathrm{M}$ hydrochloric acid solution according to ASTM G1 [15] with various inhibitor concentrations mentioned above, at $303 \mathrm{~K}$. Gravimetric measurements were conducted at $303 \mathrm{~K}$ which was selected as a temperature near the room temperature for the periods of $2,5,10,24$, and $24 \mathrm{~h}$. The coupons were immersed in varying environments in a conical container with a rubber cork to ensure full suspension of the coupons. After completion of experiments, the low-carbon steel coupons were accurately weighed with an electronic balance to ensure accurate weighing calculations of low-carbon steel coupons. All the measurements were carried out 
using a digital thermostat to ensure steady temperatures. The temperature effect on the corrosion was tested gravimetrically for $5 \mathrm{~h}$ at $303,313,323$, and $333 \mathrm{~K}$. The weight loss of a low-carbon steel coupon is calculated as the weight difference in the absence and in the presence of the corrosion inhibitor after immersion in a corrosive environment. All the measurements were made in triplicate to obtain accurate data, and the results are shown in Figure 3. The corrosion rate $\left(C_{R}\right.$ in $\left.\mathrm{mm} \mathrm{y}^{-1}\right)$ and inhibition efficiency $(I E \%)$ can be evaluated from gravimetric results according to equations (1) and (2) [16],

$$
\begin{gathered}
C_{R}=\frac{87.6 w}{a t d} \\
I E \%=\frac{w_{0}-w_{i}}{w_{0}} \times 100
\end{gathered}
$$

Where $w_{0}$ is the weight loss of the tested coupons in the corrosive solution in the absence of an inhibitor, $w_{\mathrm{i}}$ is the weight loss of the tested coupons in the corrosive solution in presence of the inhibitor, w represents the weight loss (mg) of the tested coupons, $a$ represents the area of the tested coupons $\left(\mathrm{cm}^{2}\right), t$ signifies the time $(h)$, whereas $d$ is the tested coupons density in $\mathrm{g} \cdot \mathrm{cm}^{-3}$.

\subsection{Computational Study}

Quantum chemical calculations for the N-PB molecules as a corrosion inhibitor were carried out for neutral mode using the Density functional theory calculation with GAUSSIAN 03W software and the N-PB molecular structure was optimized using the B3LYP technique and 6-21G basis set [17]. Quantum parameters such as the energy of the highest occupied molecular orbital $\left(E_{\mathrm{HOMO}}\right)$, the energy of the lowest unoccupied molecular orbital $\left(E_{\mathrm{LUMO}}\right)$, the energy gap $(\Delta E)$, electronegativity $(\chi)$, hardness $(\eta)$, softness $(S)$, and the number of electrons transferred $(\Delta N)$ were also obtained according to equations (3-6) at the same level of theory $[18,19]$.

$$
\begin{gathered}
\left(\Delta E=E_{\mathrm{HOMO}}-E_{\mathrm{LUMO}}\right) \\
\eta=\frac{\Delta E}{2} \\
S=\frac{1}{\eta} \\
\chi=-\frac{1}{2}\left(E_{\text {номо }}+E_{\mathrm{LuMO}}\right)
\end{gathered}
$$

The $\Delta N$ can be evaluated according to equation (7) [20,21].

$$
\Delta N=\frac{\chi_{\mathrm{Fe}}-\chi_{\text {inh }}}{2\left(\eta_{\mathrm{Fe}}+\eta_{\text {inh }}\right)}
$$


Where $\chi_{\mathrm{Fe}}$ represents the electronegativity value of iron $\left(\chi_{\mathrm{Fe}}=7 \mathrm{eV}\right), \chi_{\mathrm{inx}}$ is the electronegativity value of $\mathrm{N}-\mathrm{PB}, \eta_{\mathrm{Fe}}$ is the hardness value of iron $\left(\eta_{\mathrm{Fe}}=0 \mathrm{eV}\right)$, whereas $\left(\eta_{\text {inh }}\right.$ is the hardness value of $\mathrm{N}-\mathrm{PB}$.

Equation (7) can be expressed according to the electronegativity and hardness values of iron as in equation (8),

$$
\Delta N=\frac{7-\chi_{\text {inh }}}{2\left(\eta_{\text {inh }}\right)}
$$

\section{Results and Discussion}

\subsection{Synthesis}

The chemical structure of the tested inhibitor which was synthesized by the condensation reaction of 4-(1H-pyrrol-1-yl)benzohydrazide and acetophenone was confirmed by spectroscopical techniques (Fourier transform infrared (FT-IR) and nuclear magnetic resonance (NMR)) and CHN analysis. FT-IR: $3312 \mathrm{~cm}^{-1}(\mathrm{~N}-\mathrm{H}$ amine $), 3082 \mathrm{~cm}^{-1}(\mathrm{C}-$ $\mathrm{H}$ aromatic), $2941 \mathrm{~cm}^{-1}\left(\mathrm{C}-\mathrm{H}\right.$ aliphatic) and $1654(\mathrm{C}=\mathrm{O}$ amide $) .{ }^{1} \mathrm{H}$ NMR $(400 \mathrm{MHz}$, DMSO-d $\left.{ }_{6}\right)$ chemical shift (ppm): $\delta 2.25(3 \mathrm{H}, \mathrm{s}), 6.42(2 \mathrm{H}, \mathrm{dd}), 7.29(1 \mathrm{H}, \mathrm{t}$, aromatic), 7.41 (2H, d, aromatic), 7.75-7.84 (4H, dd, aromatic), $10.57(\mathrm{~s}, 1 \mathrm{H}) .{ }^{13} \mathrm{C}$ NMR (400 MHz, DMSO-d ${ }_{6}$ ) chemical shift (ppm): $\delta 163.71,145.92,143.53,136.11,128.86,128.47,126.52$, 124.01, 119.55, 114.01, 110.42 and $13.99 \mathrm{ppm}$. Elemental analysis (calculated/found): C, 75.23/75.93; H, 5.65/531; N, 13.85/14.07.

\subsection{Effect of inhibitor's concentration - weight loss analysis}

The N-PB synthesized corrosion inhibitor was found to be extremely effective in inhibition of low-carbon steel corrosion. The observed changes in the corrosion rate and consequently inhibition effects are shown in Figure 3 as a function of the inhibitor concentrations used. Weight loss measurements were carried out at $303 \mathrm{~K}$. The corrosion rate decreased and therefore the inhibition efficiency improved as the inhibitor concentration was increased, as one can see in Figure 3. This shows that the inhibitor molecules are adsorbed to a larger degree on the low-carbon steel surface as the concentration is increased. The interaction between the corrosive environment and steel surface is therefore restricted. Thus, N-PB at $500 \mathrm{ppm}$ demonstrated the best inhibition efficiency estimated as $94.5 \%$. The higher inhibition effectiveness of N-PB may be due to the introduction of electron-donating active sites like amino groups in addition to pyrrole and benzene rings, that increase the efficiency of the inhibitor molecules in passing electrons to unoccupied d-orbitals of iron atoms, thus delaying the corrosion process [22]. However, there is no identifiable change in the inhibition effectiveness from an additional increase in the inhibitor concentration, as demonstrated in Figure 3. This may be caused by surface saturation. The optimal concentration is thus selected to be $500 \mathrm{ppm}$. 


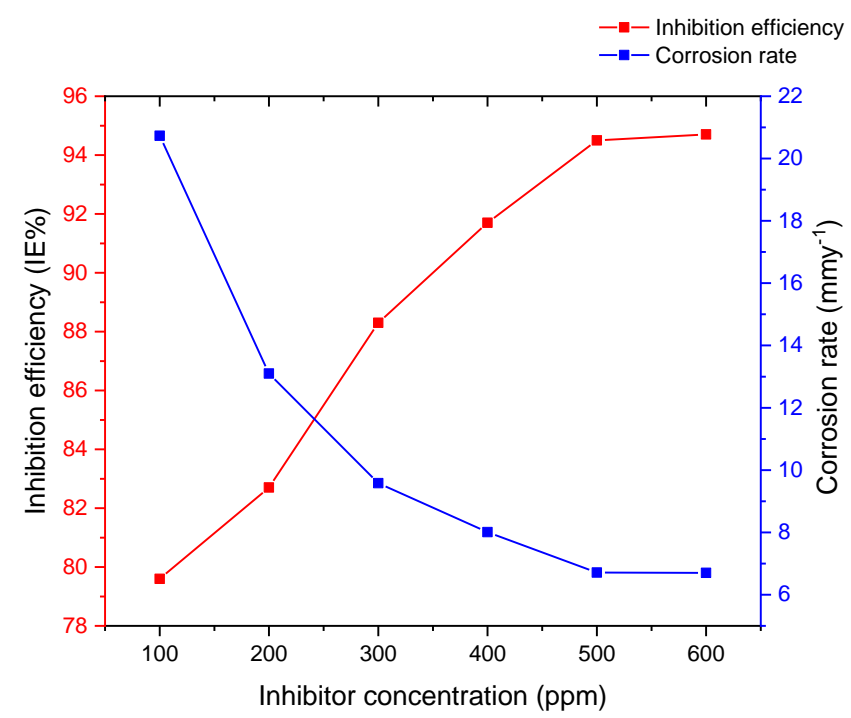

Figure 3. Corrosion rate and inhibition efficiency variation with the concentration of the synthesized inhibitor.

The inhibition efficiency-time curves of low-carbon steel in the presence of various concentrations of $\mathrm{N}-\mathrm{PB}$ in the corrosive solution are demonstrated in Figure 4 which shows that the inhibition efficiency increases as the inhibitor concentration and immersion time increase. The inhibition efficiency continues to increase upon increasing the immersion time until it reaches $94.5 \%$ at an immersion time of 5 hours, but almost no increase in the inhibition efficiency is observed at 10 hours where the inhibition efficiency reaches $95.1 \%$. When the immersion period is increased to 24 hours, the inhibition efficiency is reduced by more than $20 \%$. The reason for the decrease in the inhibition efficiency is explained based on the dissolution of the linkage between the metal and the inhibitor molecules, which leads to an increase in the corrosion rate.

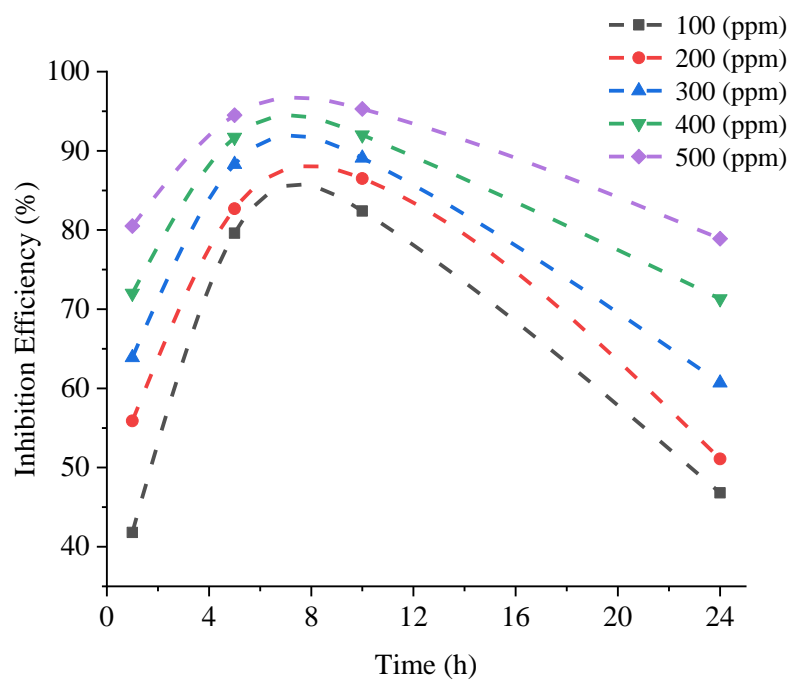

Figure 4. Inhibition efficiency - immersion period curves for low-carbon steel in the corrosive solution in the presence of various inhibitor concentrations at $303 \mathrm{~K}$. 


\subsection{Effect of solution's temperature - weight loss analysis}

The temperature effect on the corrosion rate and inhibition efficiency of the tested coupons in $1 \mathrm{M} \mathrm{HCl}$ in the presence of various inhibitor concentrations was studied by gravimetric measurements at temperatures of $303,313,323$, and $333 \mathrm{~K}$. The effect of rising temperature on the corrosion rate and inhibition efficiency obtained from gravimetric techniques is shown below.

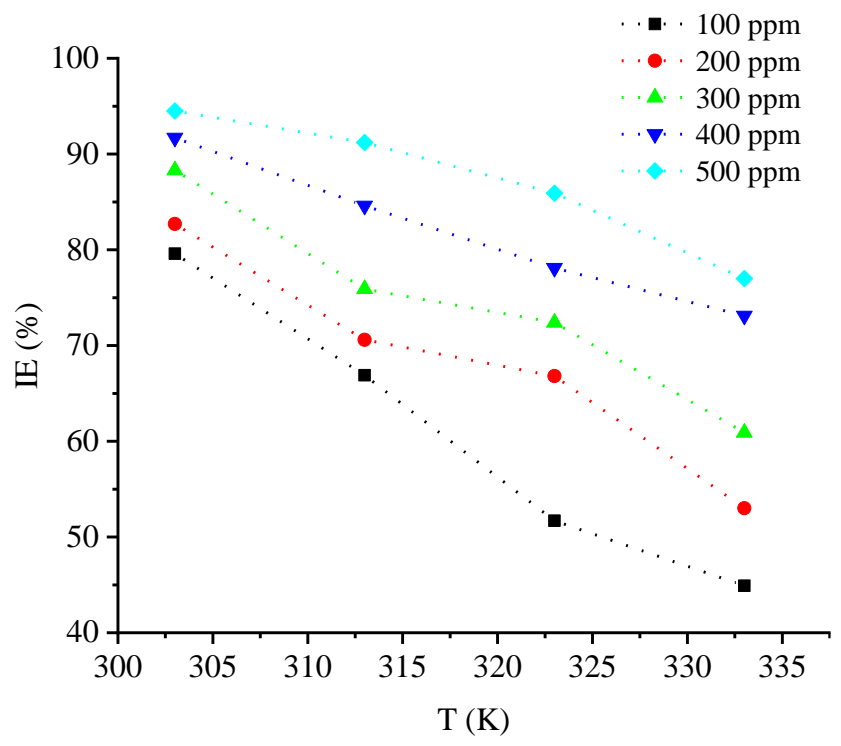

Figure 5. Inhibition efficiency - temperature curves for low-carbon steel in the corrosive solution in the presence of various inhibitor concentrations for $5 \mathrm{~h}$ exposure time.

Temperature is also found to play a significant role in the inhibitive performance of the synthesized inhibitor. It is noted from Figure 5 that the inhibition efficacy decreases with an increase in temperature. $\mathrm{N}-\mathrm{PB}$ shows efficient inhibition with significant inhibitive efficacy: $94.5 \%$ at $303 \mathrm{~K} ; 91.2 \%$ at $313 \mathrm{~K} ; 85.9 \%$ at $323 \mathrm{~K}$ and $77 \%$ at $333 \mathrm{~K}$. The explanation is that $\mathrm{N}-\mathrm{PB}$ molecules undergo chemical adsorption on the steel surface. The inhibitor-metal interaction would form coordination bonds by offering vacant orbitals of iron atoms to unshared ion pairs of nitrogen and oxygen.

The Arrhenius equation was utilized to evaluate the activation energy $\left(E_{\mathrm{a}}^{*}\right)$ of the corrosion phenomena as per equation (9),

$$
K=A_{\text {exp }}\left(-E_{\mathrm{a}}^{*} / R T\right)
$$

where $K$ represents the corrosion rate, $A$ is the Arrhenius factor, $R$ refer to the universal gas constant and $T$ reflects the absolute temperature.

Figure 6 presents the Arrhenius plot with addition of the tested inhibitor at the optimum concentration which was $500 \mathrm{ppm}$ for the immersion period of $5 \mathrm{~h}$. The activation energy value was evaluated from the slope of the linear plot which was demonstrated in Figure 6. The linear regression parameter $\left(R^{2}\right)$ was found to be very close to unity, which reflects that 
the metal corrosion in the corrosive environment can be expressed utilizing the kinetic parameters. The experimental findings demonstrate that the activation energy value in the presence of the tested inhibitor is higher than that in the absence of an inhibitor, indicating that the corrosion phenomena of low-carbon steel become slow upon addition of $\mathrm{N}-\mathrm{PB}$.

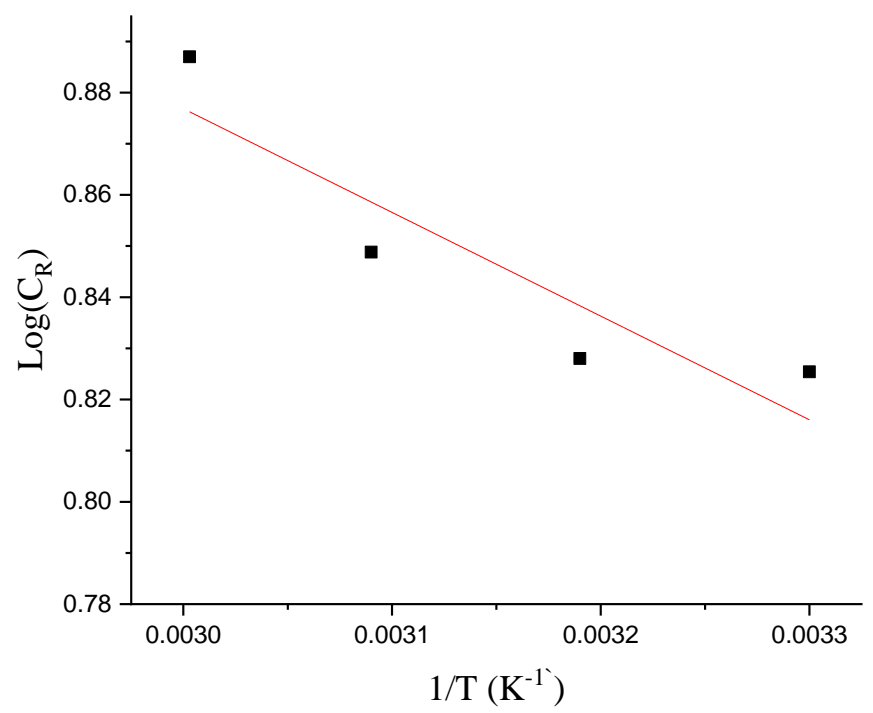

Figure 6. Arrhenius plot of $\log C_{R} v s .1 / T$ for low carbon steel in $1 \mathrm{M} \mathrm{HCl}$ in the presence of $\mathrm{N}-\mathrm{PB}$.

According to equation (9), it is obvious that the corrosion rate decreases with an increase in the activation energy. This was attributed to the formation of protected layers on the tested coupon surface that act as an energy barrier between the coupon surface and the corrosive solution [23].

The standard enthalpy of activation $\left(\Delta H_{\mathrm{a}}^{*}\right)$ and standard entropy of activation $\left(\Delta S_{\mathrm{a}}^{*}\right)$ were determined [24] according to equation (10),

$$
K=\left(\frac{R T}{N h}\right) \exp \left(\frac{\Delta S_{a}^{*}}{R}\right) \exp \left(-\frac{\Delta H_{\mathrm{a}}^{*}}{R T}\right)
$$

where $N$ represents the Avogadro number, whereas $h$ reflects the Plank constant.

A plot of $\left(\log C_{R}\right) v s .(1 / T)$ in $1 \mathrm{M} \mathrm{HCl}$ solution containing $\mathrm{N}-\mathrm{PB}$ for low carbon steel gives a straight line as illustrated in Figure 7.

According to Pournazari et al. [25], if $\left(\Delta H_{\mathrm{a}}^{*}\right)$ has a positive charge value, this indicates that the adsorption process of the inhibitor molecules is endothermic. Therefore, the adsorption of the inhibitor used is a chemical adsorption process. 


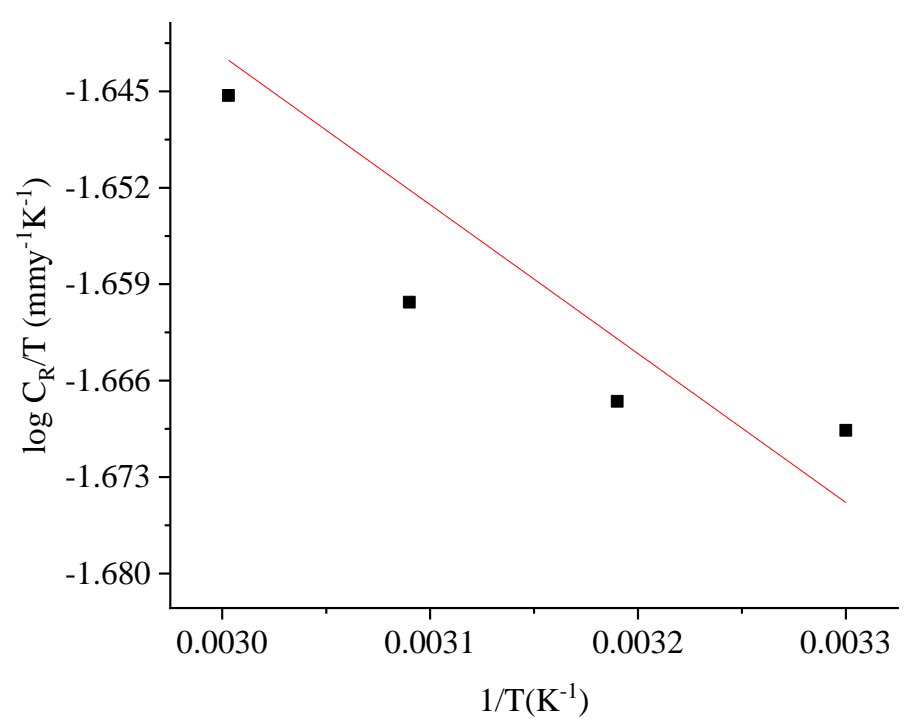

Figure 7. Plot of $\log C_{R} / T$ vs. $1 / T$ for low carbon steel in $1 \mathrm{M} \mathrm{HCl}$.

On the other hand, Li et al. [26] assumed that the increase in the entropy of the activation process include the adsorption of inhibitor (N-PB) molecules and the desorption of $\mathrm{H}_{2} \mathrm{O}$ molecules at the metal surface as in Equation (11)

$$
\mathrm{N}-\mathrm{PB}_{\text {sol }}+x \mathrm{H}_{2} \mathrm{O}_{\text {ads }} \leftrightarrow \mathrm{N}-\mathrm{PB}_{\text {ads }}+x \mathrm{H}_{2} \mathrm{O}
$$

The activation entropy value indicates an increase in the interference between the interacting molecules on the low carbon steel surface. This is another significant factor for the tested inhibitor molecules to be absorbed onto the surface of low carbon steel [27]. In the current study, the standard enthalpy of activation $\left(\Delta H_{\mathrm{a}}^{*}\right)$ was $65.19 \mathrm{~kJ} / \mathrm{mol}$ whereas the standard entropy of activation $\left(\Delta S_{\mathrm{a}}^{*}\right)$ was $-43.86 \mathrm{~J} / \mathrm{mol} \mathrm{K}$. These values indicate that adsorption occurs as a chemisorption process.

\subsection{Adsorption isotherms}

Adsorption isotherms will produce the key knowledge about the inhibitor-metal surface interaction [27]. Different adsorption models are suggested concerning this method [28, 29]. Herein, the adsorption process of $\mathrm{N}-\mathrm{PB}$ molecules was approximated by the Langmuir adsorption isotherm model as in equation (12) [30, 31].

$$
\frac{C}{\theta}=\frac{1}{K}+C
$$

where, $K$ represents the adsorption equilibrium constant and $\theta$ is the surface coverage value.

Figure 8 represents the Langmuir adsorption model. The straight plot of $C / \theta v s . C$ is found with a correlation coefficient close to 1, and the slope values in the Langmuir equation are almost 1 . These findings confirm that the adsorption of $\mathrm{N}-\mathrm{PB}$ molecules on the tested coupon surface follows the Langmuir adsorption model. 


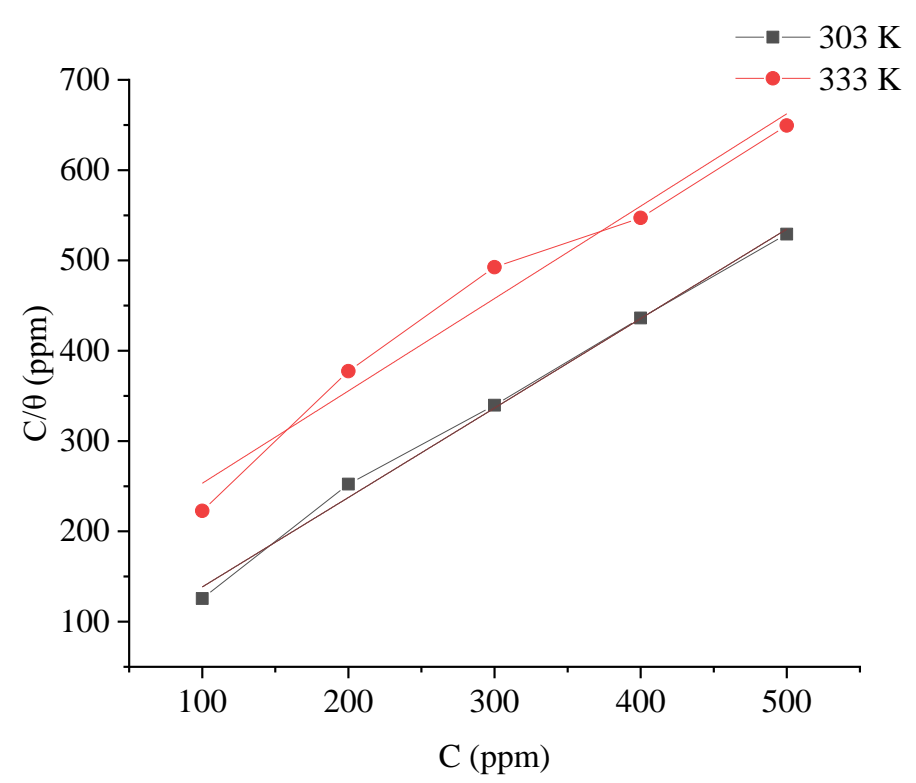

Figure 8. Langmuir's adsorption model of N-PB.

From the intercept of Langmuir's adsorption model plotted in Figure 8, the $K_{\text {ads }}$ value was evaluated at $303 \mathrm{~K}$. Using the $K_{\text {ads }}$ value, the free energy $\left(\Delta G_{\text {ads }}^{0}\right)$ value was calculated according to the equation (13):

$$
\Delta G_{\text {ads }}^{0}=-R T \ln \left(55.5 K_{\text {ads }}\right)
$$

where the value of 55.5 is the water concentration $(M), R$ and $T$ are the universal gas constant and absolute temperature $(K)$, respectively. The $\Delta G_{\text {ads }}^{0}$ value at $303 \mathrm{~K}$ was $-39.1 \mathrm{~kJ} / \mathrm{mol}$. It is usually admitted that the adsorption type is physical adsorption (electrostatic interactions) if the $\Delta G_{\text {ads }}^{0}$ value is up to $-20.0 \mathrm{~kJ} / \mathrm{mol}$, while it believed to be chemical adsorption (transfer of free electrons from inhibitor molecules to the unoccupied d-orbital of iron atoms on the low-carbon steel surface and formation of a coordination complex via coordination bonds) if the $\Delta G_{\text {ads }}^{0}$ value is above $-40.0 \mathrm{~kJ} / \mathrm{mol}$. In the current investigation, the value of $\Delta G_{\text {ads }}^{0}$ suggested that the adsorption type of $\mathrm{N}-\mathrm{PB}$ molecules involves chemical adsorption (chemisorption).

\subsection{Quantum chemical studies}

The molecular modeling approach is highly helpful in the analysis of the corrosion inhibitor structure and action $[32,33]$. From the optimized structure of the tested molecule as in Figure 9, various thermodynamic factors were computer-generated from Gaussian output files at B3LYP/6-311G(d,p). In order to predict inhibitor adsorption sites, Mulliken charges is used [34].

The findings in Table 2 demonstrate that the most favorable sites to adsorb this inhibitor onto the low-carbon steel surface by interaction from donor to acceptor were both oxygen $[\mathrm{O}(8)]$ and nitrogen $[\mathrm{N}(9)]$ in molecules of $\mathrm{N}-\mathrm{PB}$. In addition, the $\mathrm{N}-\mathrm{PB}$ molecules have 
pyrrole and benzene rings that facilitate the development of an adsorbate-surface complex [35].

Table 2. Mulliken population of N-PB molecule.

\begin{tabular}{cccccc}
\hline Atoms & $\begin{array}{c}\text { Mulliken } \\
\text { charges }\end{array}$ & Atoms & $\begin{array}{c}\text { Mulliken } \\
\text { charges }\end{array}$ & Atoms & $\begin{array}{c}\text { Mulliken } \\
\text { charges }\end{array}$ \\
\hline $\mathrm{C}(1)$ & 0.3792 & $\mathrm{O}(8)$ & -0.36 & $\mathrm{C}(15)$ & -0.1231 \\
$\mathrm{C}(2)$ & -0.1296 & $\mathrm{~N}(9)$ & -0.3025 & $\mathrm{C}(16)$ & -0.0623 \\
$\mathrm{C}(3)$ & -0.0486 & $\mathrm{~N}(10)$ & -0.0464 & $\mathrm{C}(17)$ & -0.2113 \\
$\mathrm{C}(4)$ & -0.182 & $\mathrm{~N}(11)$ & -0.1039 & $\mathrm{C}(18)$ & -0.0289 \\
$\mathrm{C}(5)$ & 0.1036 & $\mathrm{C}(12)$ & -0.1263 & $\mathrm{C}(19)$ & -0.1013 \\
$\mathrm{C}(6)$ & -0.1728 & $\mathrm{C}(13)$ & -0.1874 & $\mathrm{C}(20)$ & -0.1362 \\
$\mathrm{C}(7)$ & -0.0537 & $\mathrm{C}(14)$ & -0.1873 & $\mathrm{C}(21)$ & -0.12 \\
\hline
\end{tabular}

The HOMO has the ability to show the electron contributing sites of the inhibitor molecules [36]. Generally, the frontier MO (HOMO) of N-PB molecules which are depicted in Figure 9 has the ability to contribute its electrons to the unoccupied d-orbital of iron atoms of the low-carbon steel surface at the oxygen and nitrogen atoms. On the other hand, the LUMO refers to the electron accepting ability of the inhibitor molecules. The LUMO pictorial in Figure 9 elucidates that the accepting sites of $\mathrm{N}-\mathrm{PB}$ are identical. In the $\mathrm{N}-\mathrm{PB}$ molecules, the LUMO positions which are more active are found all over the molecule.

Optimized structure

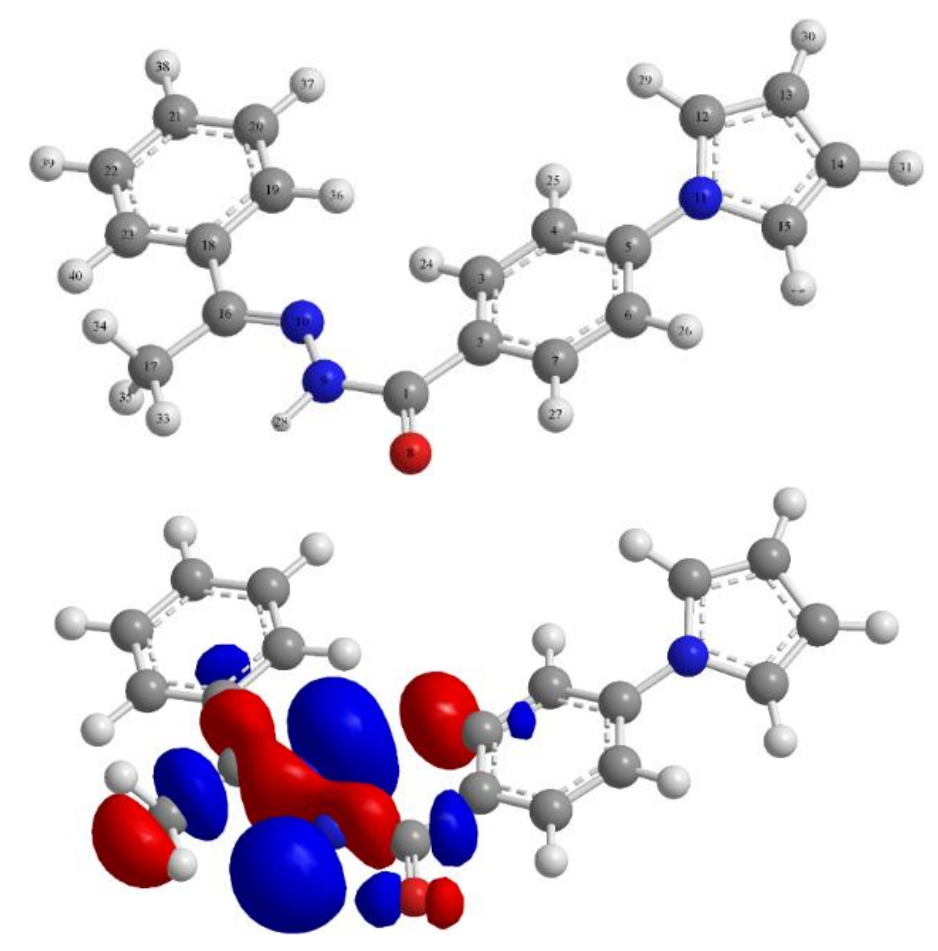

HOMO 
LUMO

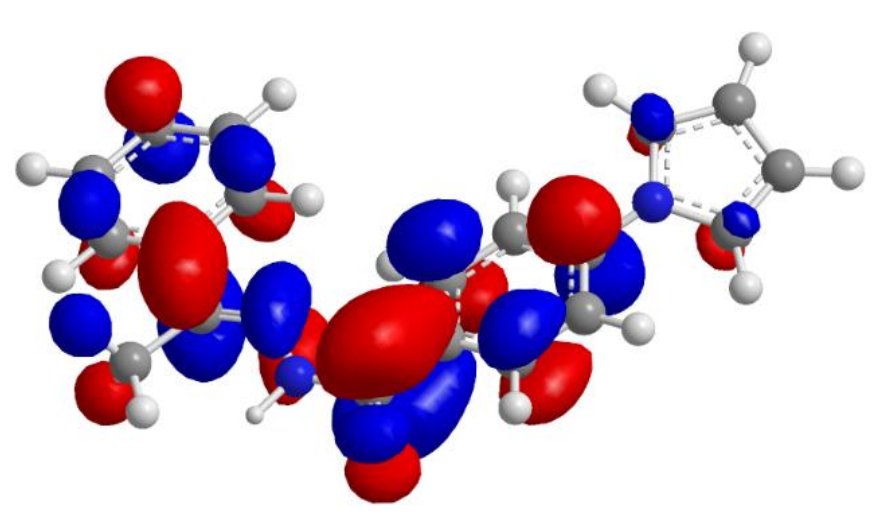

Figure 9. HOMO and LUMO of N-PB.

The quantum chemical parameters such as frontier MOs (HOMO and LUMO), energy gap, electronegativity, hardness, softness, and the number of electrons transferred $(\Delta N)$ are evaluated and demonstrated in Table 3.

Table 3. Quantum chemical parameters for $\mathrm{N}-\mathrm{PB}$ molecules using the B3LYP technique and 6-21G basis set.

\begin{tabular}{ccccccc}
\hline $\boldsymbol{E}_{\text {номо }}(\mathrm{eV})$ & $\boldsymbol{E}_{\mathrm{LuMO}}(\mathrm{eV})$ & $\boldsymbol{\Delta E}(\mathbf{e V})$ & $\chi(\mathbf{e V})$ & $\boldsymbol{\eta}(\mathbf{e V})$ & $\boldsymbol{S}(\mathbf{e V}-\mathbf{1})$ & $\Delta \boldsymbol{N}$ \\
\hline-9.243 & -4.484 & -4.759 & 6.8635 & 2.3795 & 0.4202 & 0.0286 \\
\hline
\end{tabular}

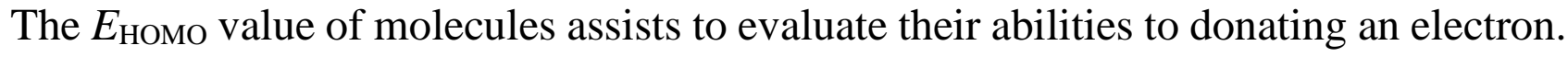
Hence, the molecules with a high energy value of HOMO can readily give electrons to a suitable molecule that has an unoccupied orbital and low energy value [37]. From Table 3, the $E_{\mathrm{HOMO}}$ value of $\mathrm{N}-\mathrm{PB}(-9.243 \mathrm{eV})$ which agrees with the experimental findings.

The LUMO energy is the molecule's ability to receive electrons. The low-value LUMO energy of the molecules represents the high ability of those molecules to accept electrons [38]. Hardness is the variation of the chemical potential $(\mu)$ on the whole atoms of a molecule [39]. The molecules with a high value of hardness represent the high stability of the same molecules. Global softness $(S)$ is the inverse of hardness and is the quantum feature of electron cloud polarization in molecules [38]. The greater the energy gap, the lower the polarity of the molecule and thus the difficulty in absorbing this molecule on the steel surface. Thus, a characteristic corrosion inhibitor has low energy gap values as well as absolute toughness but should also possess a high value of universal softness. According to the values in Table 3, the inhibition ability of $\mathrm{N}-\mathrm{PB}$ molecules is superior [39]. In addition, the $\Delta N$ value of $\mathrm{N}-\mathrm{PB}$ is positive indicating that $\mathrm{N}-\mathrm{PB}$ can exchange electrons more strongly. In summary, the quantum chemical parameters $\left(E_{\mathrm{LuMO}}, E, \eta, \sigma\right.$ and $\left.N\right)$ of $\mathrm{N}-\mathrm{PB}$ show good agreement with the experimental results obtained as mentioned above.

Surface morphology studies

The steel surface was characterized by scanning electron microscopy (SEM; Hitachi TM1000 tabletop microscope). The morphology studies were carried out using low-carbon steel coupons exposed to $1 \mathrm{M} \mathrm{HCl}$ without and with addition of $500 \mathrm{ppm} \mathrm{N}-\mathrm{PB}$. The 
exposure time was 5 hours. Figures 10a and 10b refer to the SEM images of the coupon's surface in $1 \mathrm{M} \mathrm{HCl}$ without and with addition of $\mathrm{N}-\mathrm{PB}$. The coupon surface becomes damaged when immersed in the corrosive solution, as shown in Figure 10a. On the other hand, in the presence of $500 \mathrm{ppm}$ of N-PB as shown in Figure 10b, the coupon surface remained smooth and unchanged which was due to the formation of protective layers on the coupon surface.

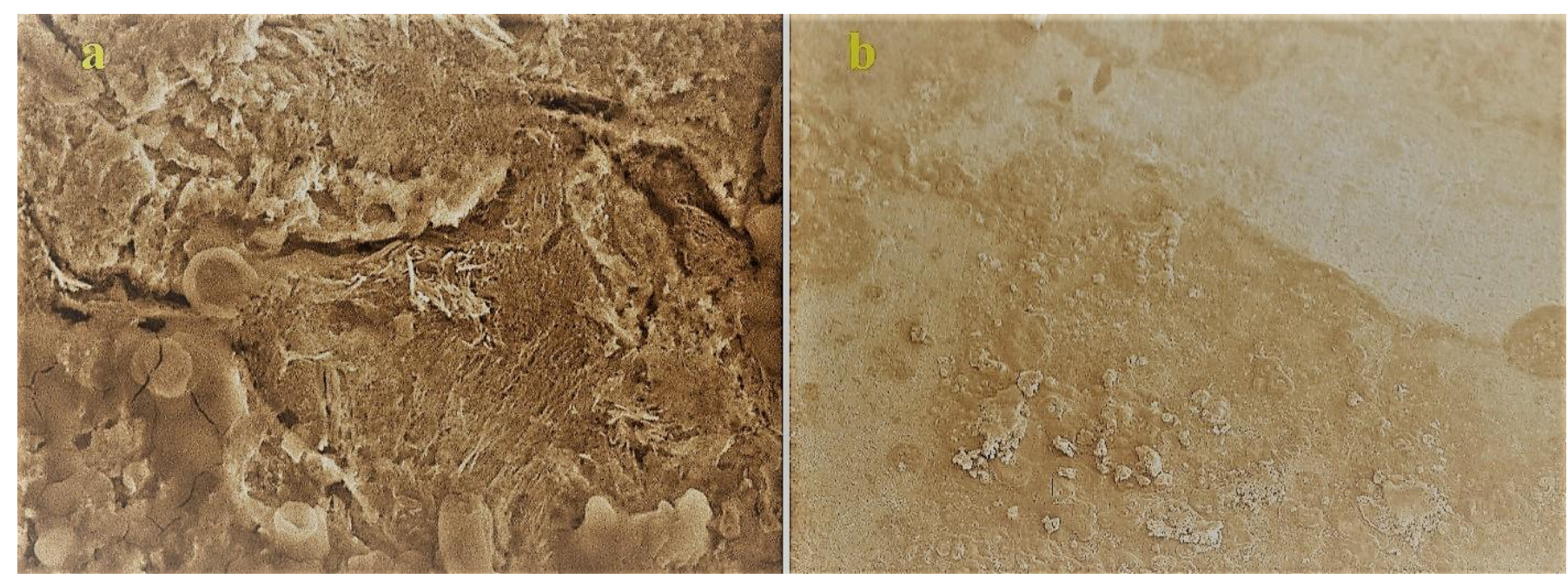

Figure 10. SEM photographs of low-carbon steel surface in $1 \mathrm{M} \mathrm{HCl}$ media exposed for $5 \mathrm{~h}$ : (a) without inhibitor, (b) with $500 \mathrm{ppm} \mathrm{N}-\mathrm{PB}$.

\section{Conclusions}

Corrosion inhibition studies, quantum chemical calculations, and adsorption isotherm models of $N^{\prime}$-(1-phenylethylidene)-4-(1H-pyrrol-1-yl)benzohydrazide (N-PB) on lowcarbon steel in $1 \mathrm{M}$ hydrochloric acid solution have been performed. The experimental and theoretical findings exhibit that:

1. The inhibition efficiency tested on low carbon steel in $1 \mathrm{M}$ solution of $\mathrm{HCl}$ increases with increasing concentration of the tested inhibitor, and the highest inhibitory efficacy of 94.5\% was reached at $500 \mathrm{ppm}$ of $\mathrm{N}-\mathrm{PB}$.

2. The adsorption isotherm process obeyed the Langmuir adsorption isotherm model.

3. The value of free energy in our measurements suggested that the adsorption of $\mathrm{N}-\mathrm{PB}$ molecules involves chemisorption.

4. The morphology studies of the surface of low-carbon steel coupons by a scanning electron microscope also prove the formation of a protective film that covers the coupon surface.

Hence, the experimental and theoretical findings confirm that the $\mathrm{N}-\mathrm{PB}$ molecules have the ability to be an efficient corrosion inhibitor. 


\section{References}

1. G.E. Badr, The role of some thiosemicarbazide derivatives as corrosion inhibitors for Csteel in acidic media, Corros. Sci., 2009, 51, no. 11, 2529-2536, doi: 10.1016/i.corsci.2009.06.017

2. T.A. Salman, D.S. Zinad, S.H. Jaber, M. Al-Ghezi, A. Mahal, M.S. Takriff and A.A. AlAmiery, Effect of 1,3,4 thiadiazole scaffold on the corrosion inhibition of mild steel in acidic medium: an experimental and computational study, J. Bio Tribocorros., 2019, 5, 1-11. doi: $10.1007 / \mathrm{s} 40735-019-0243-7$

3. H.J. Habeeb, H.M. Luaibi, R.M. Dakhil, A.A.H. Kadhum, A.A. Al-Amiery and T.S. Gaaz, Development of new corrosion inhibitor tested on mild steel supported by electrochemical study, Results Phys., 2018, 8, 1260-1267. doi: 10.1016/j.rinp.2018.02.015

4. M. Goyal, S. Kumar, I. Bahadur, C. Verma and E.E. Ebenso, Organic corrosion inhibitors for industrial cleaning of ferrous and non-ferrous metals in acidic solutions: A review, J. Mol. Liq., 2018, 256, 565-573. doi: 10.1016/j.molliq.2018.02.045

5. S.K. Saha, A. Dutta, P. Ghosh, D. Sukul and P. Banerjee, Novel Schiff-base molecules as efficient corrosion inhibitors for mild steel surface in $1 \mathrm{M} \mathrm{HCl}$ medium: experimental and theoretical approach, Phys. Chem. Chem. Phys., 2016, 18, 17898-17911. doi: 10.1039/C6CP01993E

6. A.A. Al-Amiery, A.A.H. Kadhum, A.B. Mohamad, A.Y. Musa, and C.J. Li, Electrochemical study on newly synthesized chlorocurcumin as an inhibitor for mild steel corrosion in hydrochloric acid, Materials, 2013, 6, no. 12, 5466-5477. doi: $10.3390 / \mathrm{ma6125466}$

7. S. Junaedi, A.A.H. Kadhum, A.A. Al-Amiery, A.B. Mohamad and M.S. Takriff, Synthesis and characterization of novel corrosion inhibitor derived from oleic acid: 2amino5-oleyl-1,3,4-thiadiazol (AOT), Int. J. Electrochem Sci., 2012, 7, no. 4, 35433554.

8. A. Kadhim, A. Al-Okbi, D.M. Jamil A.Q. Ahmed A.A. Al-Amiery, T.S. Gaaz, A.A.H. Kadhum, A.B. Mohamad and M.H. Nassir, Experimental and theoretical studies of benzoxazines corrosion inhibitors, Results Phys., 2017, 7, 4013-4019. doi: 10.1016/j.rinp.2017.10.027

9. A. Dutta, S.K. Saha, P. Banerjee, A.K. Patra and D. Sukul, Evaluating corrosion inhibition property of some Schiff bases for mild steel in $1 \mathrm{M} \mathrm{HCl}$ : competitive effect of the heteroatom and stereochemical conformation of the molecule, RSC Adv., 2016, 6 , 74833-74844. doi: 10.1039/C6RA03521C

10. A.A. Al-Amiery, T.A. Salman, K.F. Alazawi, L.M. Shaker, A.A.H. Kadhum and M.S. Takriff, Quantum chemical elucidation on corrosion inhibition efficiency of Schiff base: DFT investigations supported by weight loss and SEM techniques, Int. J. LowCarbon Technol., 2020, 15, no. 2, 202-209. doi: 10.1093/ijlct/ctz074 
11. A.A. Al-Amiery, L.M. Shaker, A.H. Kadhum and M.S. Takrif, Synthesis, characterization and gravimetric studies of novel triazole-based compound, Int. J. LowCarbon Technol., 2020, 15, 164-170.

12. A.A. Al-Amiery, Anti-corrosion performance of 2-isonicotinoyl-nphenylhydrazinecarbothioamide for mild steel hydrochloric acid solution: Insights from experimental measurements and quantum chemical calculations, Surface Review and Letters, 2021, 28, no. 3, 2050058.

13. M.M. Hanoon, A.M. Resen, A.A. Al-Amiery, A.A.H. Kadhum and M.S. Takriff, Theoretical and Experimental Studies on the Corrosion Inhibition Potentials of 2-((6Methyl-2-Ketoquinolin-3-yl)Methylene) Hydrazinecarbothioamide for Mild Steel in 1 $\mathrm{M} \mathrm{HCl}$, Progress in Color, Colorants and Coatings, 2021, 15, no. 1, 21-33.

14. Al-Baghdadi, T.S. Gaaz, T. Al-Adili, A.A. Al-Amiery and M. Takriff, Experimental studies on corrosion inhibition performance of acetylthiophene thiosemicarbazone for mild steel in $\mathrm{HCl}$ complemented with DFT investigation, Int. J. of Low-Carbon Tec., 2021, 16, 181-188.

15. ASTM G1. Standard Practice for Preparing, Cleaning, and Evaluating Corrosion Test Specimens; ASTM, 1999.

16. A.K. Singh, A.K. Pandey, P. Banerjee, S.K. Saha, B. Chugh, S. Thakur, B. Pani, P. Chaubey and G. Singh, Eco-Friendly Disposal of Expired Anti-Tuberculosis Drug Isoniazid and Its Role in the Protection of Metal, J. Environ. Chem. Eng., 2019, 7, no. 2, 102971. doi: $10.1016 /$ j.jece.2019.102971

17. M.J. Frisch, G.W. Trucks, H.B. Schlegel, G.E. Scuseria, M.A. Robb, J.R. Cheeseman, G. Scalmani, V. Barone, B. Mennucci, G.A. Petersson, H. Nakatsuji, M. Caricato, X. Li, H.P. Hratchian, A.F. Izmaylov, J. Bloino, G. Zheng, J.L. Sonnenberg, M. Hada, M. Ehara, K. Toyota, R. Fukuda, J. Hasegawa, M. Ishida, T. Nakajima, Y. Honda, O. Kitao, H. Nakai, T. Vreven, J.A. Montgomery, Jr., J.E. Peralta， F. Ogliaro, M. Bearpark, J.J. Heyd, E. Brothers, K.N. Kudin, V.N. Staroverov, R. Kobayashi, J. Normand, K. Raghavachari, A. Rendell， J.C. Burant， S.S. Iyengar， J. Tomasi， M. Cossi， N. Rega， J.M. Millam, M. Klene, J.E. Knox, J.B. Cross, V. Bakken, C. Adamo, J. Jaramillo, R. Gomperts, R.E. Stratmann, O. Yazyev, A.J. Austin, R. Cammi, C. Pomelli, J.W. Ochterski, R.L. Martin, K. Morokuma, V.G. Zakrzewski, G.A. Voth, P. Salvador, J.J. Dannenberg, S. Dapprich， A.D. Daniels， Ö. Farkas， J.B. Foresman， J.V. Ortiz， J. Cioslowski and D.J. Fox, Gaussian 09, Revision C.01, Gaussian, Inc., Wallingford CT, 2009.

18. N.M. Hashim, A.A. Rahim, H. Osman and P.B. Raja, Quinazolinone Compounds as Corrosion Inhibitors for Mild Steel in Sulfuric Acid Medium, Chem. Eng. Commun., 2012, 199, 751-766. doi: $10.1080 / 00986445.2011 .617801$

19. T.P. Zhao and G.N. Mu, The adsorption and corrosion inhibition of anion surfactants on aluminium surface in hydrochloric acid, Corros. Sci., 1999, 41, 1937-1944.

20.E. Bayol，K. Kayakirilmaz and M. Erbil, The inhibitive effect of hexamethylene tetramine on the acid corrosion of steel, Mater. Chem. Phys., 2007, 104, 74-82. 
21. Sh. Pournazari, M.H. Moayed and M. Rahimizadeh, In situ inhibitor synthesis from admixture of benzaldehyde and benzene-1,2-diamine along with $\mathrm{FeCl} 3$ catalyst as a new corrosion inhibitor for mild steel in 0.5 M sulphuric acid, Corros. Sci., 2013, 71, 20-31. doi: $10.1016 /$ j.corsci.2013.01.019

22. X. Li, S. Deng, H. Fu and T. Li, Adsorption and inhibition effect of 6benzylaminopurine on cold rolled steel in $1.0 \mathrm{M} \mathrm{HCl}$, Electrochim. Acta, 2009, 54, no. 16, 4089-4098. doi: 10.1016/j.electacta.2009.02.084

23. O.J. Redlich and D.L. Peterson, A Useful Adsorption Isotherm, J. Phys. Chem., 1959, 63, no. 6, 1024. doi: $10.1021 / \mathrm{j} 150576 \mathrm{a} 611$

24. K.Y. Foo and B.H. Hameed, Insights into the modeling of adsorption isotherm systems, Chem. Eng. J., 2010, 156, no. 1, 2-10. doi: 10.1016/j.cej.2009.09.013

25. A.S. Fouda and A. Hussein, Role of Some Phenylthiourea Derivatives as Corrosion Inhibitors for Carbon Steel in HCl Solution, J. Korean Chem. Soc., 2012, 56, no. 2, 264273. doi: $10.5012 / \mathrm{jkcs} .2012 .56 .2 .264$

26. M. Hosseini, S.F.L. Mertens, M. Ghorbani and M.R. Arshadi, Asymmetrical Schiff bases as inhibitors of mild steel corrosion in sulphuric acid media, Mater. Chem. Phys., 2003, 78, no. 3, 800-808. doi: 10.1016/s0254-0584(02)00390-5

27. L.B. Richardson, The adsorption of carbon dioxide and ammonia by charcoal, J. Am. Chem. Soc., 1917, 39, no. 9, 1828-1848. doi: 10.1021/ja02254a005

28. T. Peme, L.O. Olasunkanmi, I. Bahadur, A.S. Adekunle, M.M. Kabanda and E.E. Ebenso, Adsorption and Corrosion Inhibition Studies of Some Selected Dyes as Corrosion Inhibitors for Mild Steel in Acidic Medium: Gravimetric, Electrochemical, Quantum Chemical Studies and Synergistic Effect with Iodide Ions, Molecules, 2015, 20, no. 9,16004-16029. doi: 10.3390/molecules200916004

29. L.C. Murulana, A.K. Singh, S.K. Shukla, M.M. Kabanda and E.E. Ebenso, Experimental and Quantum Chemical Studies of Some Bis(trifluoromethyl-sulfonyl) Imide Imidazolium-Based Ionic Liquids as Corrosion Inhibitors for Mild Steel in Hydrochloric Acid Solution, Ind. Eng. Chem. Res., 2012, 51, 13282-13299. doi: 10.1021/ie300977d

30. H. Zarrok, M. Assouag, A. Zarrouk, H. Oudda, A. Hallaoui, R. Touzani, M. Allali, B. Hammouti, M.El. Hezzat and M. Bouachrine, Quantum chemical study on the corrosion inhibition of some bipyrazoles, Res. J. Pharm., Biol. Chem. Sci., 2015, 6, $1853-1860$.

31. G. Gece, The use of quantum chemical methods in corrosion inhibitor studies, Corros. Sci., 2008, 50, no. 11, 2981-2992. doi: 10.1016/j.corsci.2008.08.043

32. I.B. Obot, D.D. Macdonald and Z.M. Gasem, Density functional theory (DFT) as a powerful tool for designing new organic corrosion inhibitors. Part 1: An overview, Corros. Sci., 2015, 99, 1-30. doi: 10.1016/j.corsci.2015.01.037

33. R.L. Camacho-Mendoza, E. Gutiérrez-Moreno, E. Guzmán-Percástegui, E. AquinoTorres, J. Cruz-Borbolla, J.A. Rodríguez-Ávila, J.G. Alvarado-Rodríguez, O. OlveraNeria, P. Thangarasu and J.L. Medina-Franco, Density Functional Theory and 
Electrochemical Studies: Structure-Efficiency Relationship on Corrosion Inhibition, J. Chem. Inf. Model., 2015, 55, no. 11, 2391-2402. doi: 10.1021/acs.jcim.5b00385

34. N. Khalil, Quantum chemical approach of corrosion inhibition, Electrochim. Acta, 2003, 48, no. 18, 2635-2640. doi: 10.1016/s0013-4686(03)00307-4

35. E.E. Ebenso, D.A. Isabirye and N.O. Eddy, Adsorption and quantum chemical studies on the inhibition potentials of some thiosemicarbazides for the corrosion of mild steel in acidic medium, Int. J. Mol. Sci., 2010, 11, no. 6, 2473-2498. doi: 10.3390/ijms11062473

36. R.G. Parr and R.G. Pearson, Absolute hardness: companion parameter to absolute electronegativity, J. Am. Chem. Soc., 1983, 105, 7512-7516. doi: 10.1021/ja00364a005

37. P. Singh, M. Kumar, M.A. Quraishi, J. Haque and G. Singh, Bispyranopyrazoles as Green Corrosion Inhibitors for Mild Steel in Hydrochloric Acid: Experimental and Theoretical Approach, ACS Omega, 2018, 3, no. 9, 11151-11162. doi: 10.1021/acsomega.8b01300

38. T. Zhao and G. Mu, The adsorption and corrosion inhibition of anion surfactants on aluminium surface in hydrochloric acid, Corros. Sci., 1999, 41, no. 10, 1937-1944. doi: 10.1016/s0010-938x(99)00029-3

39. M. Gopiraman, N. Selvakumaran, D. Kesavan, I.S. Kim and R. Karvembu, Chemical and Physical Interactions of 1-Benzoyl-3,3-Disubstituted Thiourea Derivatives on Mild Steel Surface: Corrosion Inhibition in Acidic Media, Ind. Eng. Chem. Res., 2012, 51, no. 23, 7910-7922. doi: $\underline{10.1021 / i e 300048 t}$ 